\section{Prevalence Rates of Antiphospholipid Antibodies in Ischemic Stroke Patients}

Hirohisa Okuma ${ }^{1}$, Yasuhisa Kitagawa ${ }^{2}$, Satoko Kobori ${ }^{1}$, Sari Sekiyama ${ }^{3}$ and Shigeharu Takagi ${ }^{3}$

Key words: antiphospholipid antibodies, ischemic stroke

\section{(DOI: 10.2169/internalmedicine.45.6042)}

In cerebrovascular disorders with an underlying immune abnormality, antiphospholipid antibodies, of which there are numerous types, are the leading cause of thrombosis in the absence of acquired risk factors (1). To define and characterise these antibodies, we studied their prevalence rates in patients who had experienced cerebral infarction, and investigated the relationships among the antibodies.

This study involved 250 patients, 155 males and 95 females (average age 72 years), with cerebral infarction who visited our hospitals. Of these patients, one male and four females (average age 39 years) had systemic lupus erythematosus (SLE) as an underlying disease. Levels of antiphospholipid antibodies, including $\beta 2$-glycoprotein I-dependent anticardiolipin antibody ( $\beta 2-\mathrm{GPI} \mathrm{aCL}), \mathrm{IgG}$ anticardiolipin antibody (IgG aCL), lupus anticoagulant (LA), phosphatidylserine-dependent antiprothrombin antibody (PS/PT), antiphosphatidylserine antibody (PS), and antiphosphatidylinositol antibody (PI), were determined in the 250 patients. The level of antinuclear antibody was also measured in patients positive for PI or PS. Assessment of the presence of various antibodies was carried out in patients in the chronic stage, at least 1 month after the onset of all type of cerebral infarction.

Fig. 1 shows the prevalence rates of the antibodies in the 250 patients with cerebral infarction. They were $2.8 \%$ (7/ 250 ) for $\beta 2-\mathrm{GPI}$ aCL, $12.0 \%$ (30/250) for IgG aCL, $9.2 \%$ (23/250) for LA, 7.2\% (18/250) for PS/PT, 9.6\% (24/250) for PS, and $8.8 \%$ (22/250) for PI. Among the 23 patients positive for LA, 18 (78.2\%) were also positive for PS/PT. Patients aged 50 years or under accounted for $5.2 \%$ of the 250 patients (13/250), and of these, 5 had underlying SLE ( 1 male and 4 females, average age 39 ). Of these 5 patients, $80 \%$ (4/5) were positive for both $\beta 2$-GPI aCL and LA, and $40 \%$ were positive for PI or PS as well as $\beta 2$-GPI aCL or LA. One was negative for $\beta 2$-GPI aCL and LA, and positive for PI, PS, and PS/PT.

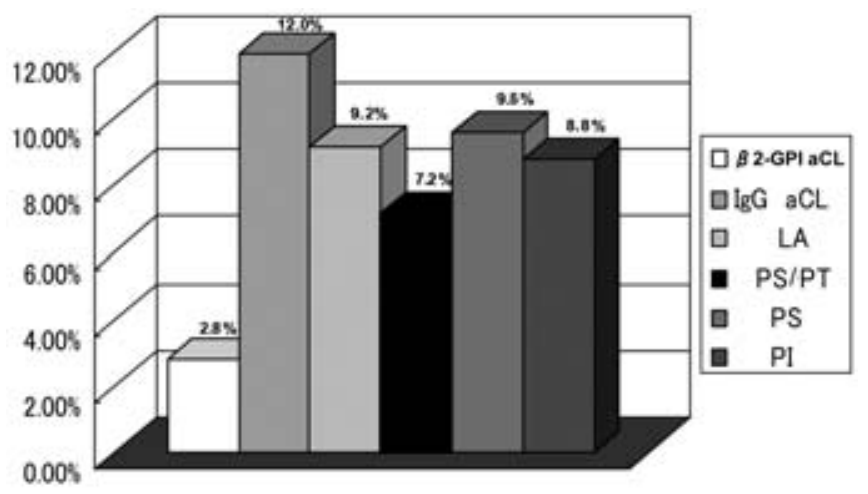

Figure 1. The incidences of $\beta 2$-glycoprotein I-dependent anticardiolipin antibody ( $\beta 2$-GPI aCL), IgG anticardiolipin antibody (IgG aCL), lupus anticoagulant (LA), phosphatidyIserine-dependent antiprothrombin antibody (PS/PT), antiphosphatidylserine antibody (PS), antiphosphatidylinositol antibody (PI).

Among the 250 patients, 13.6\% (34/250) were positive for either PI or PS, and 6.8\% (17/250) were positive for both. Of the 34 patients positive for either PI or PS, $8.8 \%$ (3/34) were positive for LA and $8.8 \%$ (3/34) were positive for $\beta 2$-GPI aCL, with $70.6 \%$ (24/34) positive for antinuclear antibody. One patient was positive for all of PI, PS, $\beta 2$-GPI aCL, LA, and antinuclear antibody.

Previous reports have suggested that the presence of antiphospholipid antibody is a risk factor for cerebral infarction in those aged under 45 or 50 years (2). The Antiphospholipid Antibodies in Stroke Study (APASS) (3) reported that in patients with antiphospholipid antibody, the risk of cerebral infarction was 2.31 times higher than in those negative for the antibody, and Brey et al (4) reported a 1.5 times higher risk over an observation period of 20 years. In our study of 250 patients with cerebral infarction, the prevalence rates of the antiphospholipid antibodies $\beta 2-$ GPI aCL, LA, PI, PS, and PS/PI were higher in patients aged 50 or under with underlying SLE than in those without SLE, suggesting that the presence of antiphospholipid antibody may be a risk factor for cerebral infarction in young adult in SLE patients. Antiphospholipid antibodies include anticardiolipin antibody, LA, and antibodies specific to anionic phospholipids, including PS and PI (5). As mentioned above, PI and PS were detected in $9.6 \%$ and $8.8 \%$, respectively, of the 250 patients with cerebral infarction, and $79.2 \%$ of these patients tested positive for antinuclear antibody. Of the 250 patients, there

\footnotetext{
${ }^{1}$ Department of Neurology, Tokai University Tokyo Hospital, Tokyo, ${ }^{2}$ Department of Neurology, Tokai University Hachioji Hospital, Tokyo and ${ }^{3}$ Department of Neurology, Tokai University School of Medicine, Tokyo

Received for publication May 17, 2006; Accepted for publication June 29, 2006

Correspondence to Dr. Hirohisa Okuma, Department of Neurology, Tokai University Tokyo Hospital, 1-2-5 Yoyogi, Shibuya-ku, Tokyo 1510053
} 
were 13 aged 50 or under (average age 43), 4 of whom were positive for PI and PS antibodies, suggesting that the presence of these antibodies should be determined in order to assess the risk of cerebral infarction in young adult. We consider that PS and PT, as well as $\beta 2-$ GPI aCL and LA, are important in screening for antiphospholipid antibodies, and are recommended to be regarded as antibodies associated with cerebral infarction.

\section{References}

1. The Antiphospholipid Antibodies in Stroke Study Group. -Clinical and laboratory findings in patients with antiphospholipid antibodies and cerebral ischemia. Stroke 21: 1268-1273, 1990.

2. Brey RL. Management of the neurological manifestations of APS - what do the trials tell us? Thromb Res 114: 489-499, 2004.

3. The Antiphospholipid Antibodies in Stroke Study (APASS) Group. Anticardiolipin antibodies are an independent risk factor for first ischemic stroke. Neurology 43: 2069-2073, 1993.
4. Brey RL, Abbott RD, Curb JD, et al. $\beta 2$-Glycoprotein 1dependent anticardiolipin antibodies and risk of ischemic stroke and myocardial infarction. The Honolulu Heart Program Stroke 32: 1701-1706, 2001.

5. Tuhrim S, Rand JH, Wu X, et al. Antiphosphatidyl serine antibodies are independently associated with ischemic stroke. Neurology 53: 1523-1527, 1999.

(C) 2006 The Japanese Society of Internal Medicine http://www.naika.or.jp/imindex.html 